\title{
Fault Tolerant Dual-Motor Drives: Sizing of Power Electronic
}

\author{
Tiago José dos Santos Moraes ${ }^{1}$, Ngac Ky Nguyen ${ }^{1}$, Fabien Meinguet ${ }^{2}$, Eric Semail ${ }^{1}$ \\ ${ }^{1}$ Electrical Engineering and Power Laboratory of Lille (L2EP) \\ Arts et Métiers ParisTech, Lille, France \\ ${ }^{2}$ Thales Alenia Space, Charleroi, Belgium \\ E-mail. ${ }^{1}\{$ tiago.dossantosmoraes ;ngacky.nguyen ; eric.semail\}@ensam.eu \\ ${ }^{2}$ fabien.meinguet@thalesaleniaspace.com
}

\section{Keywords}

« Series connected », « Multiphase drive », « Open-winding », « Fault tolerance », « Inverter dimensioning », «TVC system », « Multi-machine system », « Aerospace »

\begin{abstract}
This paper analyzes two dual-motor fault-tolerant topologies. The first one supplies independently both machines while the second one connects them in series for reducing the number of transistors. For a given DC-link voltage, the converter component sizing is based on the peak current obtained in the normal and degraded modes.
\end{abstract}

\section{Introduction}

Capability of degraded functioning is highly required in several specific applications as aeronautics and aerospace [1]. When a fault occurs, it is necessary to have some supplementary degrees of freedoms (DoF) for ensuring an acceptable functioning. For short-duration faults, the power-converter components are generally the more sensitive devices since the thermal time constants of a machine are larger. Nevertheless the torque pulsations of the motor must be acceptable for the mechanical load. For long-duration faults, machine thermal constraints must be added. In inverter-machine drives, the case analyzed in this paper, the supplementary DoF are achieved by a high number of inverter legs and/or multiphase machines [2][3]. Numerous papers have studied only the impact of open-circuit fault [4], considering either that the short-circuit fault of inverter switch can lead to an open-phase circuit using additional power, or that the short-circuit currents are acceptable thanks to a proper design of the machine with sufficiently high values of inductances [5].

The particular application considered in the paper is an aerospace Thrust Vector Control (TVC) system. It is composed of two actuators that orientate the thruster in order to control the rocket trajectory (Fig. 1 and 2). In the past these actuators were hydraulic while they are replaced by electromechanic motors in this study. The electrical structure must withstand open-circuit fault and shortcircuit fault of inverter switches, without increasing too much the system cost and weight. In the presented paper, a structure composed of two open-winding six-phase machines connected in series (Fig. 4.) is compared with another more classical solution using two open-winding motors being each one independently supplied by an H-bridge inverter (Fig. 3).

The series-connection between the two machines (Fig. 4) halves the number of transistors and consequently also the number of drivers comparing to the solution using one H-bridge structure (Fig. 3). Consequently, it is expected that global price of the inverters and the mass can be reduced if the constraints on each power converter component do not increase too much. Furthermore, one 
fundamental advantage of the series winding connection is that it increases automatically the value of inductive component leading thus to reduced amplitudes of high frequency current components.

On the contrary, the global copper losses and, consequently, the global consumption rise because even if only one machine is driven, the currents are crossing both machines. As a consequence, the interest of the proposed solution depends on the ratio between the running costs and the investment costs and also on the impact of the mass. For aerospace applications with short time mission such as thruster, the global efficiency can be negligible in comparison with the investment cost and the impact of a lower mass.

However, to ensure the independent control of two series-connected machines, a specific coupling between them is required. Some papers, like [6], demonstrated theoretically that the number of independent currents (DoF) has to be higher than twice the number of machines connected in series if the back-electromotive forces (back-EMFs) are sinusoidal. In the case where the machines are nonsinusoidal, a more complex formulation is required [7]. Different experimental set-ups, as [8], have proven that the concept can be practically achieved for induction and synchronous machines.

In this paper, a design of the inverters for a TVC system is presented, based on an index taking into account the product of the number of components and their highest peak current in degraded mode.

The paper is organized as follows. Section II describes the TVC system. In section III, two topologies are proposed and analyzed. Section IV specifies the simulation conditions and some results are given. Section V ends the paper with a conclusion.

\section{TVC System}

Thrust Vector Control (TVC) system controls the turbine orientation to guide the rocket trajectory. This system is composed of two mechanical actuators, placed spatially $90^{\circ}$ from each other around the turbine (Fig. 1), for the movement in two axes, assuming that the actuators are independent. As the movement of the turbine is measured with the inclination angle between the turbine axis and the rocket axis $\left(\theta-\right.$ between $0^{\circ}$ and $6^{\circ}$ ) (Fig. 2) and its direction $\left(\varphi-\right.$ between $0^{\circ}$ and $\left.360^{\circ}\right)$, the region of actuation is represented as a circle. So the highest effort of an actuator is when the direction of inclination is on its own axis.

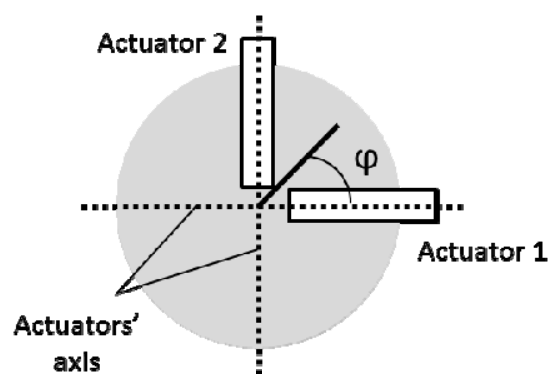

Fig. 1: Up view with actuators' axis and the direction of inclination angle $(\varphi)$ 

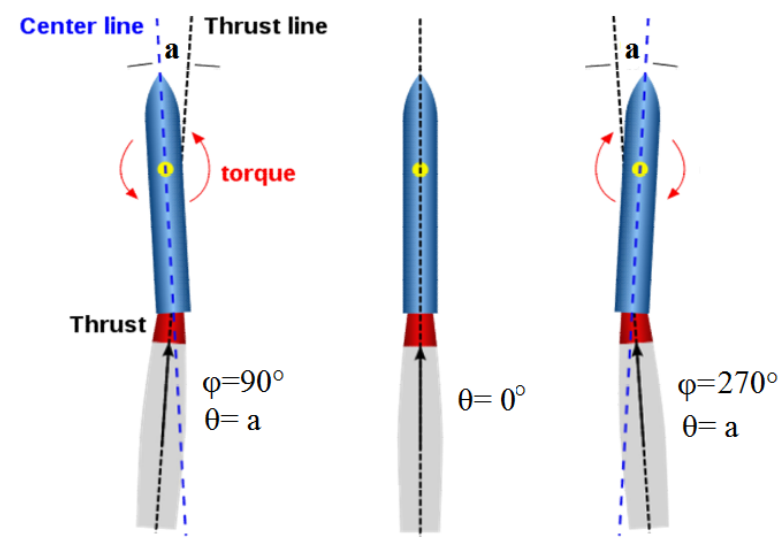

Fig. 2: Torque generation representation for 3 different thrust inclinations

Up to now, the actuators are mostly hydraulic cylinders having some drawbacks as the high tank volume and the liquid's high pressure which can damage the whole launcher. One of solution is to use electro-mechanical systems to replace the hydraulic cylinders. The tank is replaced by a battery, which can be recharged during the actuator's braking period. However, electronic inverters are less reliable than mechanical systems. Consequently, fault-tolerant capability of the machine drive is mandatory to ensure a functioning when a fault occurs.

\section{Modeling of Fault-Tolerance Topologies}

Both topologies analyzed in this study have two six-phase open-end winding motors. In a high power application, having 6 phases is better than 3 since the power per phase is reduced and the DoF of a sixphase machine allow a faulty operation. In open-end winding machines, impacts created by the faulty phase to the others are less important than with a classical wye-coupling machine [1]. However, openend winding drives need a higher number of components because two isolated-inverters are needed.

The first topology shown in Fig. 3, named as H-bridge, is composed of two machines supplied independently. This structure presents a high number of transistors (48 in 24 inverter legs) and the two machines can of course be independently controlled. This structure is already found in some applications as naval and aeronautics.

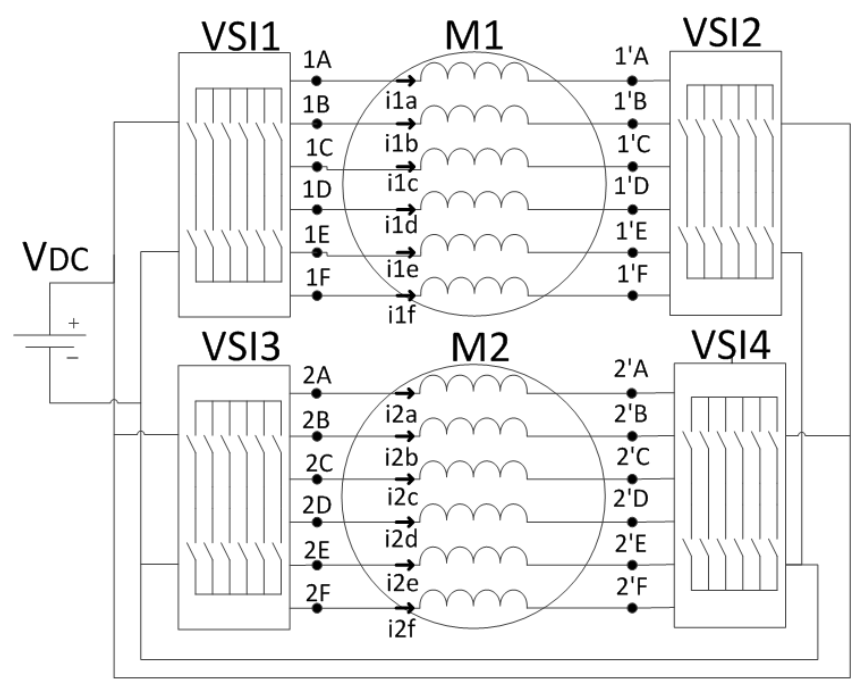

Fig. 3: H-bridge structure 
The RIMM (Redundant Inverter Multiple Machines) topology, shown in Fig. 4, connects the two motors in series to half the number of transistors, in comparison with the previous topology. The advantage of this reduction of transistors is, beside the investment cost reduction, a mass reduction which is a major problem in aerospace industry.

Two batteries supply the structure ensuring thus also a redundancy in terms of energy source. The voltage between the two negative points of the batteries $\mathrm{v}_{\mathrm{n} \ln 2}$ can be controlled to increase the system performance in case of short-circuit inverter fault [3].

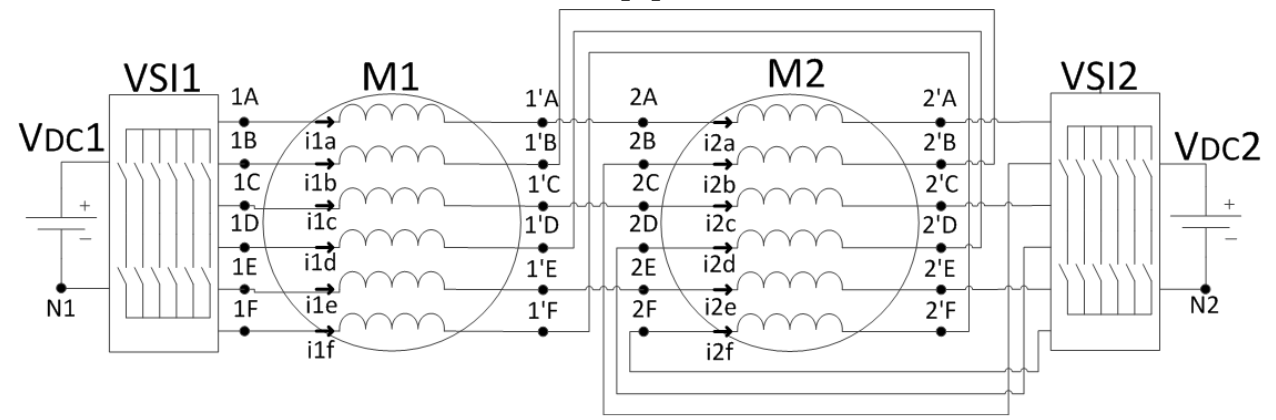

Fig. 4: RIMM structure

A special coupling between the machines ensures an independent control of each machine's torque as shown in the following equations: Equation (1) represents the coupling in a form of a matrix $([\mathrm{K}])$, showing the relation of the currents of M1 and M2.

$$
\left[I_{2}\right]=[K]\left[I_{1}\right] \rightarrow\left[i_{2 a} i_{2 b} i_{2 c} i_{2 d} i_{2 e} i_{2 f}\right]^{T}=\left[\begin{array}{cccccc}
1 & 0 & 0 & 0 & 0 & 0 \\
0 & -1 & 0 & 0 & 0 & 0 \\
0 & 0 & 1 & 0 & 0 & 0 \\
0 & 0 & 0 & -1 & 0 & 0 \\
0 & 0 & 0 & 0 & 1 & 0 \\
0 & 0 & 0 & 0 & 0 & -1
\end{array}\right]\left[i_{1 a} i_{1 b} i_{1 c} i_{1 d} i_{1 e} i_{1 f}\right]^{T}
$$

Applying a specific 6-phase Concordia transformation to equation (1), a 6-phase machine is decomposed into two homopolar machines and two diphase machines. Each fictitious machine interacts with some back-EMF harmonics to generate a torque, as shown in Tab. 1 for a 6-phase symmetrical machine.

\section{Tab. 1: Harmonic EMF for each fictitious machine}

\begin{tabular}{|l|l|l|l|l|}
\hline $\begin{array}{l}\text { 6-phases } \\
\text { machines }\end{array}$ & $\begin{array}{l}\text { First homopolar } \\
\text { machine }\left(h_{1}\right)\end{array}$ & $\begin{array}{l}\text { Second homopolar } \\
\text { machine }\left(h_{2}\right)\end{array}$ & $\begin{array}{l}\text { Main machine } \\
(m \alpha m \beta)\end{array}$ & $\begin{array}{l}\text { Secondary machine } \\
(s \alpha s \beta)\end{array}$ \\
\hline $\begin{array}{l}\text { Back-EMF } \\
\text { harmonics }\end{array}$ & $\mathrm{H} 0, \mathrm{H} 6, \mathrm{H} 12, \ldots$ & $\mathrm{H} 3, \mathrm{H} 9, \ldots$ & $\begin{array}{l}\mathrm{H} 1, \mathrm{H} 5, \mathrm{H} 7, \mathrm{H} 11 \\
\ldots\end{array}$ & $\begin{array}{l}\mathrm{H} 2, \mathrm{H} 4, \mathrm{H} 8, \mathrm{H} 10, \\
\ldots\end{array}$ \\
\hline
\end{tabular}

As shown in Tab. 1, the $1^{\text {st }}$ homopolar machine $\left(h_{l}\right)$ and the secondary machine $(s \alpha s \beta)$ are resulted from the even harmonics of the back-EMFs after the Concordia transformation. In general, a symmetrical machine does not have the even harmonics. It means that no torque can be created by these two fictitious machines, but only parasitic currents can be induced in the two homopolar machines.

Using the Concordia transformation the equation (1) can be expressed as (2): 


$$
\left[I_{1_{\alpha \beta}}\right]=\left[C_{6}\right][K]^{-1}\left[C_{6}\right]^{T}\left[I_{2_{\alpha \beta}}\right]=\left[\begin{array}{cccccc}
0 & 1 & 0 & 0 & 0 & 0 \\
1 & 0 & 0 & 0 & 0 & 0 \\
0 & 0 & 0 & 0 & 1 & 0 \\
0 & 0 & 0 & 0 & 0 & -1 \\
0 & 0 & 1 & 0 & 0 & 0 \\
0 & 0 & 0 & -1 & 0 & 0
\end{array}\right]\left[I_{2_{\alpha \beta}}\right] \rightarrow\left[\begin{array}{l}
I_{h 11} \\
I_{h 21} \\
I_{m \alpha 1} \\
I_{m \beta 1} \\
I_{s \alpha 1} \\
I_{s \beta 1}
\end{array}\right]=\left[\begin{array}{c}
I_{h 12} \\
-I_{h 22} \\
I_{s \alpha 2} \\
-I_{s \beta 2} \\
I_{m \alpha 2} \\
-I_{m \beta 2}
\end{array}\right]
$$

Considering only the currents which lead to torque production, equation (2) leads to (3) and (4) as:

$$
\begin{aligned}
& {\left[\begin{array}{l}
\mathrm{I}_{\mathrm{m} \alpha 1} \\
\mathrm{I}_{\mathrm{m} \beta 1}
\end{array}\right]=\left[\begin{array}{c}
\mathrm{I}_{\mathrm{s} \alpha 2} \\
-\mathrm{I}_{\mathrm{s} \beta 2}
\end{array}\right] \rightarrow\left[\mathrm{I}_{\mathrm{m} 1}\right]=\left[\mathrm{I}_{\mathrm{s} 2}\right]^{*}} \\
& {\left[\begin{array}{l}
I_{s \alpha 1} \\
I_{s \beta 1}
\end{array}\right]=\left[\begin{array}{c}
I_{m \alpha 2} \\
-I_{m \beta 2}
\end{array}\right] \rightarrow\left[I_{s 1}\right]=\left[I_{m 2}\right]^{*}}
\end{aligned}
$$

Equations (3) and (4) can be represented graphically in Fig 5. as a series connection of the main machine of $\mathrm{M}_{1}$ ([ $\left.I_{m 1}\right]$ currents) with the secondary machine of $\mathrm{M}_{2}$ ([I $\left.I_{s 2}\right]$ currents) and vice-versa. By controlling $\left[I_{m 1}\right]$ and $\left[I_{m 2}\right]$, the torques (or speeds) of the two machines are independently controlled. Secondary machines generate losses, but no torque if even harmonics of Back-EMFs are equal to zero.

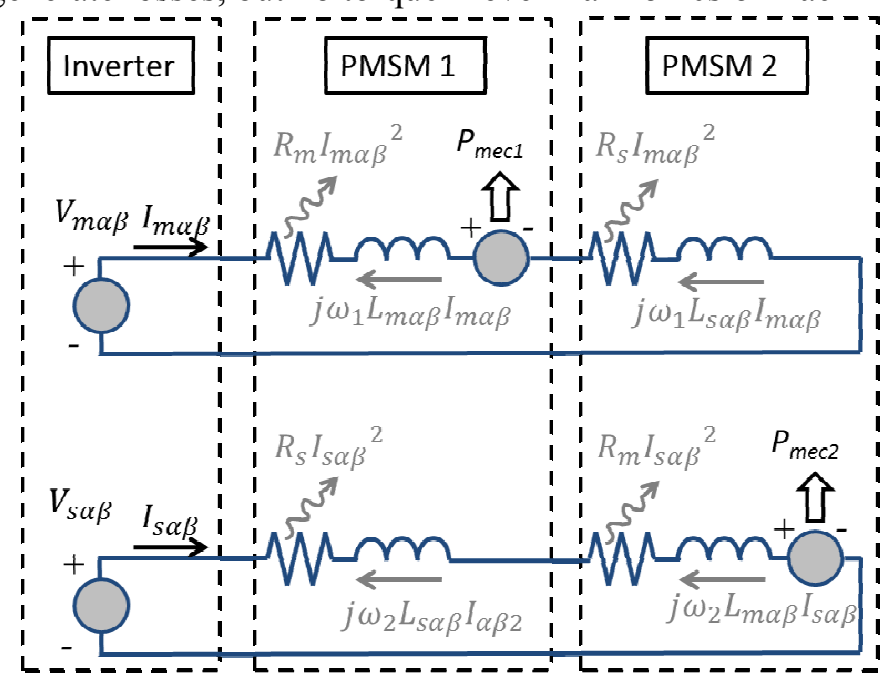

Fig. 5: Series connection of the fictitious machines

\section{Inverter Sizing}

In order to compare different topologies based on its cost and weight, a formula called Inverter Sizing (IS) is elaborated. It's considered that those parameters are proportional to two variables: the number of transistors and the transistor power sizing. While the number of transistors $\left(N b_{\text {trans }}\right)$ is simply determined by the topology, the transistor power sizing depends on, the values of the peak voltage and current which are required in order to achieve the cycle imposed by the payload. As all transistors in this paper are dimensioned to the same DC bus, the transistor power sizing is directly proportional to the highest peak-current in steady state $\left(I_{p k}\right)$. Inverter sizing is, in this case, calculated by the equation (5). As this index is only used for comparison, a per unit analysis is more convenient.

$$
I S=N b_{\text {trans }} * I_{p k}
$$

$I_{p k}$ is the higher value current peak obtained by comparing the most constraining operational points that the system might be able to achieve. For the TVC system, these operational points depend on the speed reference of the actuators and the faulty mode. 


\section{Simulation Results}

\section{A. Drive model}

Machine's parameters are not the same for both topologies because of the different voltages applied to each machine. Each machine is designed for a given DC-link voltage by changing its number of coils leading to different phase resistances, inductances and magnetic flux.

\section{B. Speed reference}

For both topologies, two different speed references are simulated: one machine (M1) at $\Omega_{\text {ref- } 1}=100$ $\mathrm{rad} / \mathrm{s}$ and both machines at $\Omega_{\text {ref-2 }}=70.7 \mathrm{rad} / \mathrm{s}$.

Both speed references represent the speed needed to achieve a maximum turbine inclination $\left(\theta=6^{\circ}\right)$. But the first speed reference represents the displacement of an actuator in its own axis $\left(\varphi=0^{\circ}\right.$ or $\left.90^{\circ}\right)$, as the second one represents the maximum displacement of the turbine in the axis between the two actuator axes $\left(\varphi=45^{\circ}\right)$. As both actuators act together in the second case, the speed reference of each one is $\sqrt{2}$ lower in comparison to the first case.

\section{Faults simulation}

As already mentioned, the most common faults will be simulated. For the studied system, these faults are: a short-circuit inverter switch and an open phase. For simulation, the top switch of the phase A of the inverter VSI1 in both topologies is short-circuited. To avoid short-circuiting the DC-bus, the bottom switch of the same leg has to be 'open', this protection is standardly found in industrialized components. An open-circuit of one phase (the phase A in our study) is also carried out in simulation.

It can be noticed that no reconfiguration of the control strategy or reduction of the speed or torque references in degraded mode have been made. So the speed and torque generated by the motors will be the same in normal and degraded functioning mode. Otherwise, considering a functioning without reconfiguration may be a simpler solution because the faulty detection and the reconfiguration implementation are sources of fault as well. The objective is to compare in term of peak currents within two topologies in order to have a pre-sizing of the inverters.

\section{Results}

Fig. 6 presents the simulation results for the two different topologies presented in section III under healthy and faulty modes at two different speeds.

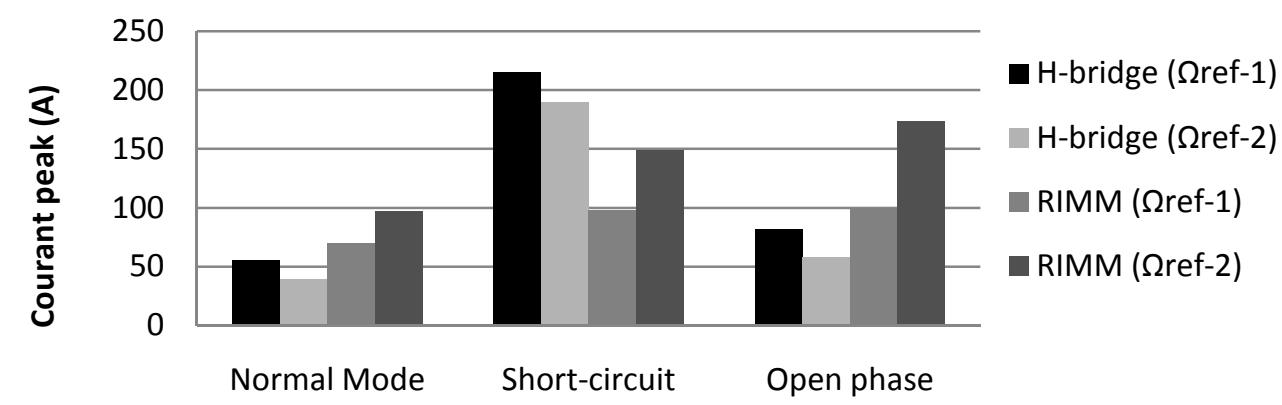

Fig. 6: Peak currents obtained under healthy and faulty operations with two proposed topologies at two speeds.

Firstly, the graphic shows different peak currents for each topology under three modes of functioning. In the H-bridge topology, the dual-motors are independently controlled. The highest amplitude of 
currents is generated when only one actuator is working at $\Omega_{\text {ref-1 }}$. On the other hand, the seriescoupling of the RIMM topology leads to a higher current peak when two machines are running since the currents are crossing the dual-motors.

As mentioned above, the criteria of dimensioning is based on the highest peak current among the ones obtained for three operation modes (healthy, short-circuit and open phase). As shown in Fig. 6, the normal mode is no constraining for dimensioning of the drive. The currents obtained in the shortcircuit fault are taken for the H-bridge topology (about 215A). For the RIMM structure, the highest amplitude of current is obtained when two machines are controlled at $\Omega_{\text {ref-2 }}$ under open-circuit fault of one phase. This amplitude is thus taken for dimensioning of the RIMM topology (about 175A).

It is obvious that the peak currents in faulty mode are higher than the ones in healthy mode because the currents in the healthy phases have to increase to reach the required speed and torque as before the fault. Furthermore, harmonic currents, which are equal to zero for both topologies in healthy mode, become non negligible in degraded mode because of the asymmetrical distribution of the currents in the machine.

Fig. 7 to Fig. 10 give the obtained currents of each topology during a switch short-circuit or open phase fault. In fact, in H-bridge structure, the current homopolar is very important in short-circuit or open-circuit fault since there is a path for its circulation. In the RIMM structure, the voltage between two negative points of two DC-buses $\mathrm{v}_{\mathrm{N} 1 \mathrm{~N} 2}$ is equal to zero in healthy mode and this voltage increases significantly in faulty mode. However there is no path for zero sequence current to circulate because of the two-isolated DC-sources, the current controllers try to balance as much as possible the voltage system. Finally, the phase currents of the H-bridge in faulty modes are more unbalanced comparing to the ones obtained in the RIMM topology.

Because of the coupling, an open-circuit affects both machines in RIMM topology. So the healthy phases' currents increase more for this structure in comparison to the H-bridge one topology.

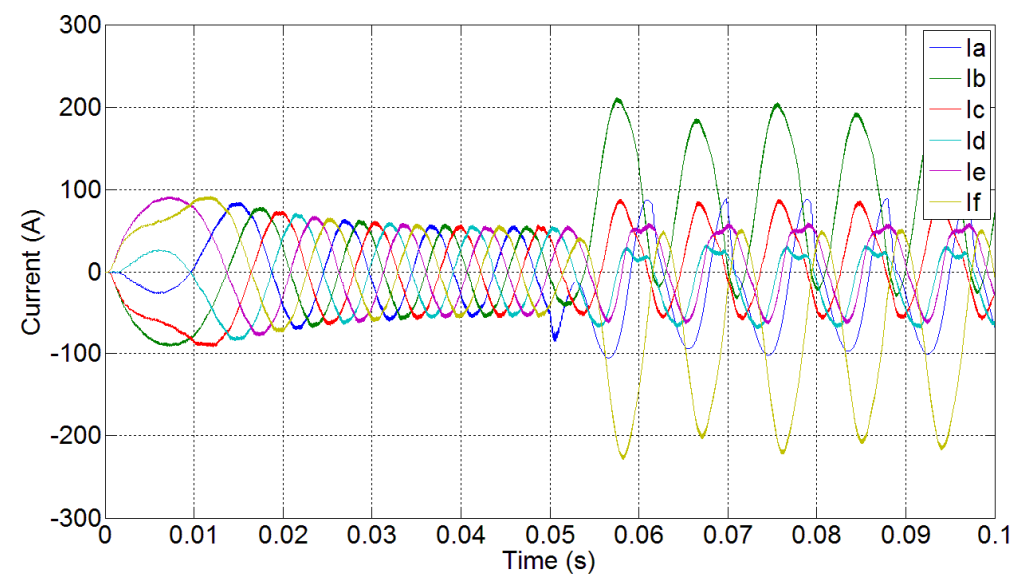

Fig. 7: H-bridge topology's currents before and after a half-leg short-circuit occurs in phase A at $0.05 \mathrm{~s}$, when driving only one machine. 


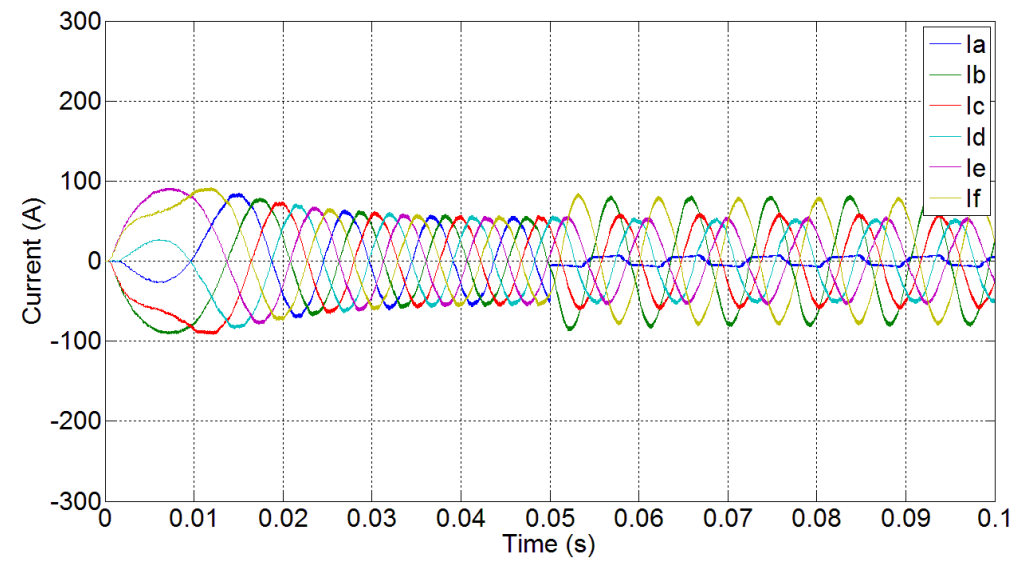

Fig. 8: H-bridge topology's currents before and after phase A opens at $0.05 \mathrm{~s}$, when driving only one machine.

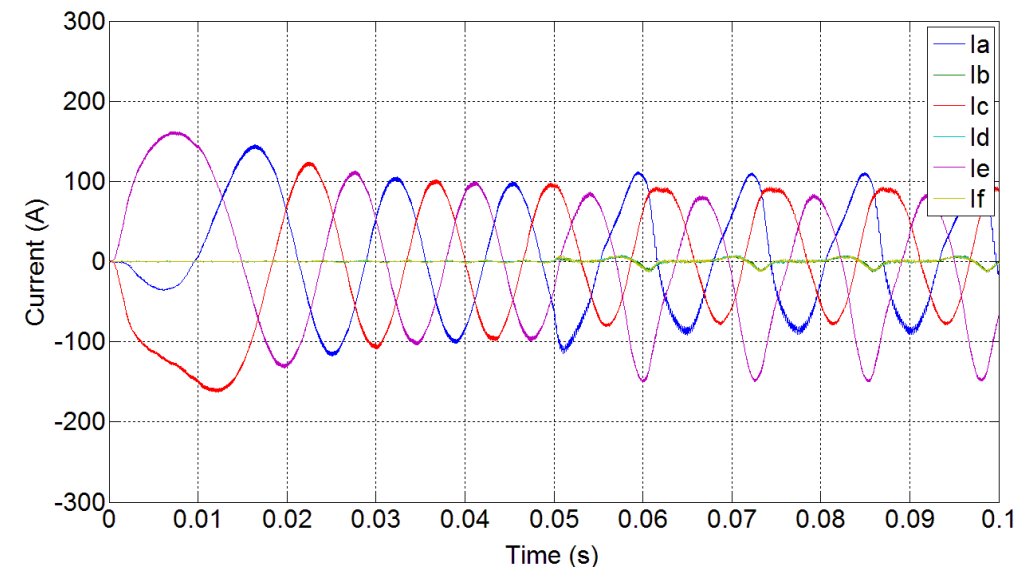

Fig. 9: RIMM topology's currents before and after a half-leg short-circuit occurs in phase A at $0.05 \mathrm{~s}$, when driving both machines.

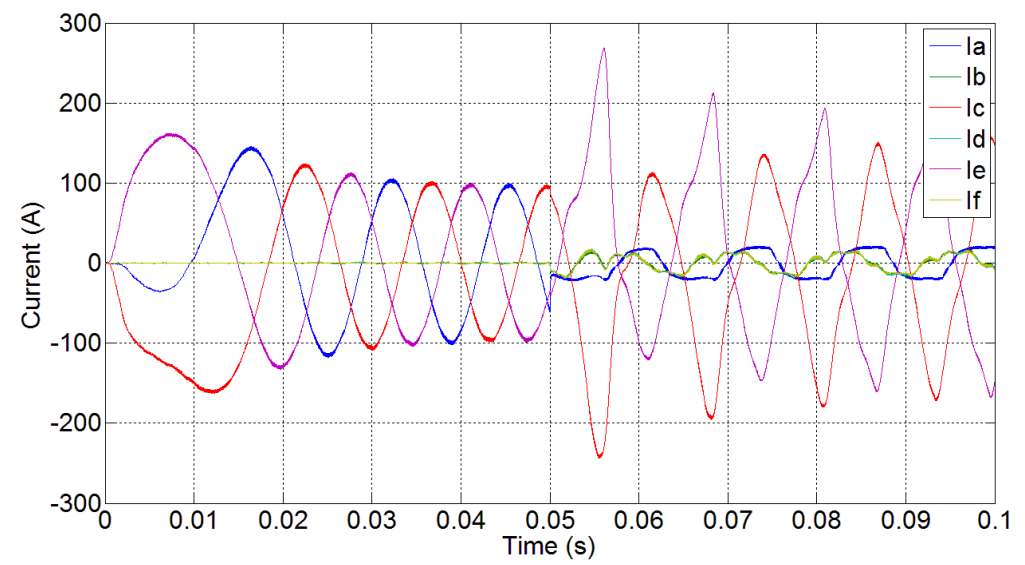

Fig. 10: RIMM topology's currents before and after phase A opens at $0.05 \mathrm{~s}$, when driving both machines.

For an inverter sizing (IS) comparison, the H-bridge has double of transistors with a peak current of phase being $20 \%$ higher than the one of a RIMM structure. Then, IS, calculated by the equation (5), is $140 \%$ higher for the H-bridge topology than the RIMM, as shown in Fig. 11. That means that H-bridge inverter is at least twice more expensive and heavier in the conditions imposed in this paper, even if its current's amplitude is lower in the normal mode. 


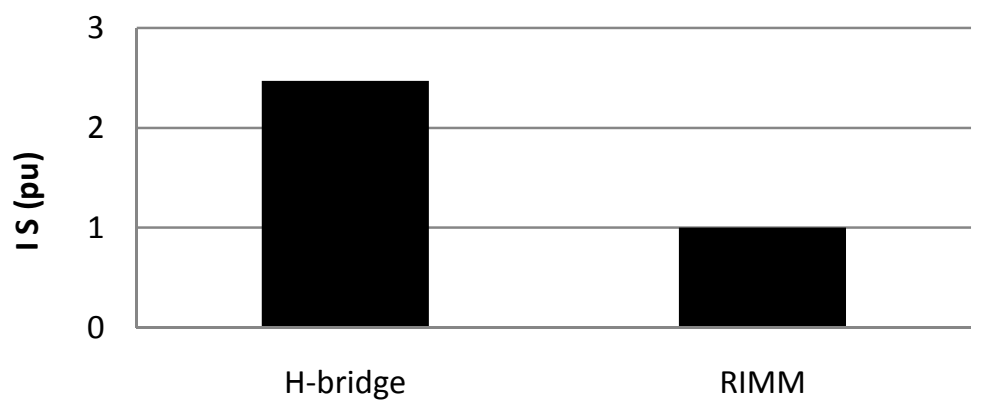

Fig. 11: Inverter sizing of both topologies

Besides the inverter sizing, which covers an economical view of the comparison, some other technical aspects must be also verified. Concerning the degraded-mode, the torque ripple should respect some limits to be considered acceptable in degraded mode. Fig. 12 and Fig. 13 present the generated torque in degraded mode for both topologies.

Among the four operational point analyzed, the torque ripple depends mostly of the faulty mode. The higher torque ripples, similar to the peak-current analysis, is during a short-circuit fault for the $\mathrm{H}$ bridge topology and for an open phase for the RIMM topology.

RIMM topology presents a higher reliability because the torque ripple is $166 \%$ in the worst case, while H-bridge topology may generate torque ripples 2,7 times higher during a short-circuit fault.

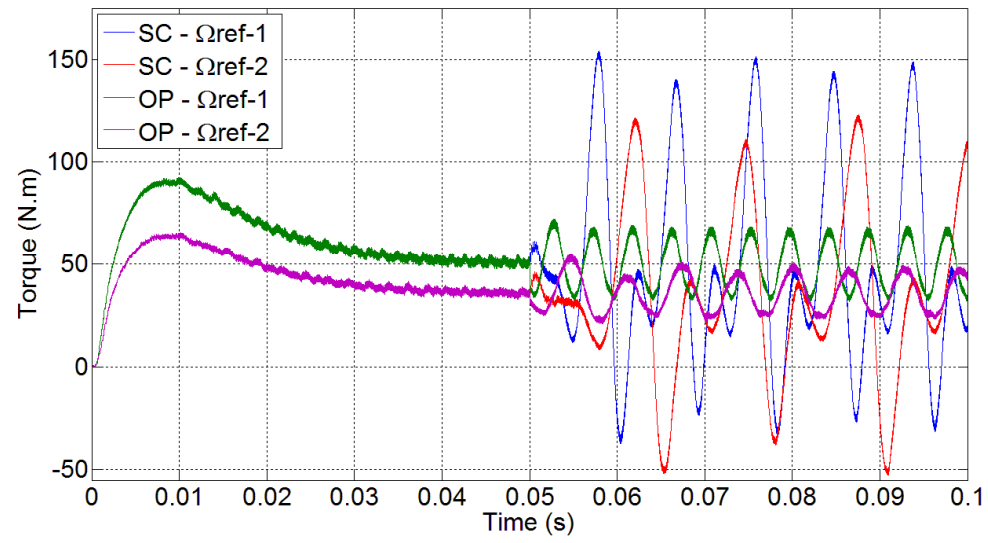

Fig. 12: Torque generated by M1 of the H-bridge topology

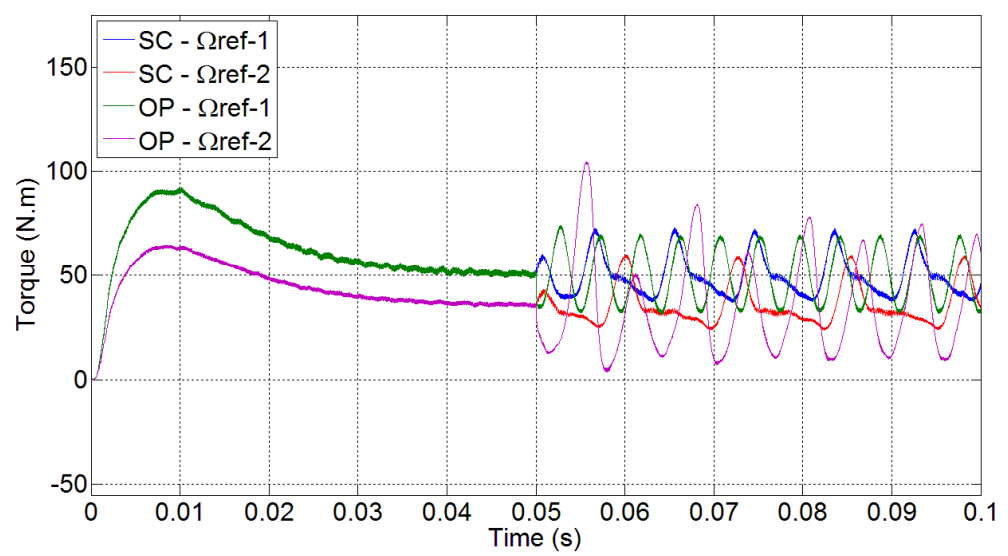

Fig. 13: Torque generated by M1 of the RIMM topology

$(\mathrm{SC}=$ Short-circuit fault; OP = Open phase fault $)$ 


\section{Conclusion}

This paper analyzes the inverter sizing of a dual 6-phase machines fault-tolerant system. As the system needs at least two machines, a series connection topology is a solution to reduce the number of transistors. Beside this, this system can be cheaper regardless the operational constraints (higher cooper losses).

Degraded mode has to be taken for dimensioning of the system because the currents of the healthy phases have to be increased to compensate the degraded one. Comparing the two proposed topologies, the RIMM structure has more advantages in term of power electronic components and power rate of inverters and lower torque ripple in degraded mode. Although there is not a series connection machine system in the industry for now, this innovated structure may find its place in high performance faulttolerant systems for specific applications like the aerospace TVC.

\section{References}

[1] J. Bennett, G. Atkinson, B. Mecrow and D. Atkinson "Fault tolerant design considerations and control strategies for aerospace drives", IEEE Trans. Ind. Electron., vol. 59, no. 5, pp.2049 -2058 2011

[2] L. de Lillo, L. Empringham, P. Wheeler, S. Khwan-On, C. Gerada , M. Othman and X. Huang "Multiphase power converter drive for fault-tolerant machine development in aerospace applications", IEEE Trans. Ind. Electron., vol. 57, no. 2, pp.575 -583 2010

[3] M. Villani, M. Tursini, G. Fabri and L. Castellini "High reliability permanent magnet brushless motor drive for aircraft application", IEEE Trans. Ind. Electron., vol. 59, no. 5, pp.2073 -2081 2012

[4] F. Baudart, B. Dehez, E. Matagne, D. Telteu-Nedelcu, P. Alexandre and F. Labrique "Torque control strategy of polyphase permanent-magnet synchronous machines with minimal controller reconfiguration under open-circuit fault of one phase", IEEE Trans. Ind. Electron., vol. 59, no. 6, pp.2632 -2644 2012

[5] F. Meinguet, N.-K. Nguyen, P. Sandulescu, X. Kestelyn, and E. Semail, "Fault-tolerant operation of an open-end winding five-phase PMSM drive with inverter faults," Industrial Electronics Society, IECON 2013 39th Annual Conference of the IEEE, Vienna, Nov. 2013, pp. 5191-5196.

[6] E. Levi, M. Jones, S.N. Vukosavic, H.A. Toliyat, "A Novel Concept of a Multiphase, Multimotor Vector Controlled Drive System Supplied From a Single Voltage Source Inverter”, IEEE Transactions on Power Electronics, vol. 19, no. 2, March 2004, pp. 320-335.

[7] E. Semail, E. Levi, A. Bouscayrol, and X. Kestelyn, "Multi-machine modelling of two series connected 5 phase synchronous machines: effect of harmonics on control," Power Electronics and Applications, 2005 European Conference, Dresden (Germany), Sept. 2005, pp. 1-10

[8] F. Mekri, J.-F. Charpentier, E. Semail, "An efficient control of a series connected two-synchronous motor 5-phase with non-sinusoidal EMF supplied by a single 5-leg VSI: Experimental and theoretical investigations," Electric Power Systems Research, vol. 92, pp. 11-19, Nov. 2012. 